Central European Journal of Energetic Materials, 2016, 13(1), 231-245

ISSN 1733-7178

e-ISSN 2353-1843

\title{
Evaluation of Potassium Perchlorate as a Burning Rate Modifier in Composite Propellant Formulations
}

\author{
Sunil JAIN, MEHILAL*, Praveen Prakash SINGH, \\ Bikash BHATTACHARYA
}

High Energy Materials Research Laboratory, Pune-411021, India ${ }^{*}$ E-mail:drmehilal@yahoo.co.in

\begin{abstract}
The burning rate of a solid composite propellant is one of its most important ballistic properties. To achieve a specified burning rate, transition metal oxides are used as burning rate modifiers. However, addition of transition metal oxides creates inertness in the composition. To avoid such inertness, an attempt has been made to incorporate potassium perchlorate (KP) as a burning rate modifier by partially replacing ammonium perchlorate (AP), up to the $10 \%$ level, and the composition was then studied in detail for its mechanical, thermal and ballistic properties. The data revealed that no change occurred in the case of the mechanical properties, however, the thermal stability decreased as the KP content was increased. The burning rate data revealed that on incorporation of $10 \% \mathrm{KP}$, there was an enhancement in the burning rate of up to $35 \%$ in comparison to the original composite propellant formulation, but beyond this no enhancement in burning rate was observed, indicating that the optimum content for KP in the composition had been reached.
\end{abstract}

Keywords: composite propellant, burning rate, ammonium perchlorate, potassium perchlorate

\section{Introduction}

Composite propellants represent an important class of solid rocket propellants, widely used in defence and space applications. In a composite propellant, solid particles are held together by a binder, usually a cross-linked rubber with processing aids [1]. The burning rate of a propellant is considered to be the single most important property governing the ballistic performance of solid 
rocket motors, and depends mostly on the particle characteristics of the oxidizer, the burning rate catalyst and the metallic fuel.

To achieve a required burning rate, transition metal oxides (TMOs) are preferred [2-6]. However, due to the inertness of TMOs and their overall effect on processibility and performance, percentages higher than $1 \%$ cannot be used. To cope with these problems, ferrocene derivatives [7] have been incorporated in propellant compositions. However, migration and sublimation of ferrocene and some of its derivatives causes, i.a. increased sensitivity, which does not allow large scale application. In further continuation of this work, grafted hydroxylterminated polybutadiene (HTPB) having ferrocenyl groups (butacene) has also been tried by many researchers and found to give promising results without compromising performance [8]. However, the use of butacene is not cost effective and as a binder it cannot be totally used in place of HTPB. Keeping in mind the performance of the composition without affecting its processibility, the application of potassium perchlorate (KP) has been envisaged as a partial replacement of ammonium perchlorate (AP). The comparative properties of AP and KP are presented in Table 1. The use of KP was reported for the first time by Boggs et al. [9] as a doping agent over AP, and resulted in large effects on the deflagration behaviour. They also reported that an increase in the percentage of $\mathrm{K}^{+}$enhanced the low pressure deflagration limit (LDL), the burning rate and the burning rate pressure index. Recently, Ishitha et al. $[10,11]$ have also doped AP with small amounts of $\mathrm{K}^{+}$and observed an enhancement in the deflagration behaviour of $\mathrm{AP}$, as the $\mathrm{K}^{+}$ions enhance the condensed phase decomposition of AP. Furthermore, Seetharamachayulu et al. [12] have reported the effect of $\mathrm{KP}$ on the combustion and thermal decomposition of a binary oxidizer system based on $\mathrm{AP}$ and $\mathrm{KP}$, and their findings revealed that the burning rate of the pellet increased up to $30 \% \mathrm{KP}$, and beyond this it decreased drastically [13].

Table 1. Comparitive properties of ammonium perchlorate and potassium perchlorate

\begin{tabular}{|l|c|c|c|c|}
\hline \multicolumn{1}{|c|}{ Oxidizer } & $\begin{array}{c}\text { Molecular } \\
\text { weight } \\
{[\mathrm{g} / \mathrm{mol}]}\end{array}$ & $\begin{array}{c}\text { Density } \\
{\left[\mathrm{kg} / \mathrm{m}^{3}\right]}\end{array}$ & $\begin{array}{c}\text { Oxygen } \\
\text { balance } \\
{[\%]}\end{array}$ & $\begin{array}{c}\text { Heat of } \\
\text { formation, } \Delta \mathrm{H}_{\mathrm{f}} \\
{[\mathrm{kJ} / \mathrm{mol}]}\end{array}$ \\
\hline Ammonium perchlorate & 117.49 & 1949 & +34.04 & -295.31 \\
\hline Potassium perchlorate & 138.55 & 2519 & +46.2 & -430.12 \\
\hline
\end{tabular}

Although a literature survey has revealed that the characteristics of complete KP-based composite propellant formulations are not very good from an applications point of view, due to solid residue in the nozzle exit, hygroscopicity 
and low heat of combustion, nevertheless KP based compositions offer high burning rates and high densities, and reduced combustion instability, which is one of the preferred criteria in the field of rocketry $[14,15]$.

Therefore, keeping in mind the advantages of KP, a systematic study has been carried out by partially replacing AP with KP as a burning rate modifier.

In the following section, the effect of KP on partial replacement of AP in composite propellant formulations based on $\mathrm{HTPB} / \mathrm{AP} / \mathrm{Al}$ is reported in detail, for its viscosity build up behaviour, and its mechanical, thermal and ballistic properties.

\section{Materials and Methods}

\subsection{Materials}

Ammonium perchlorate with an average particle size of $300 \pm 10 \mu \mathrm{m}$ was procured from M/s Pandian Chemicals Ltd., Cuddalore. Hydroxyl terminated polybutadiene, manufactured by free radical solution polymerization, with an average molecular weight of 2,500 and hydroxyl value of $43 \mathrm{mg} \mathrm{KOH} / \mathrm{g}$, was procured from M/s Anabond Ltd., Chennai. Aluminum powder, with an average particle size of $15 \pm 3 \mu \mathrm{m}$, was procured from M/s The Metal Powder Company, Madurai. Potassium perchlorate, with an average particle size of $50 \mu \mathrm{m}$, was procured from trade and used as such. Dioctyladipate (DOA) and toluene di-isocyanate (TDI) were also procured from trade and used as received. Copper chromite and iron oxide having average particle sizes of 2.5 and $1 \mu \mathrm{m}$, respectively, which were used as burning rate modifiers in the compositions, were also procured from trade and incorporated in the compositions after drying at $105^{\circ} \mathrm{C}$ for $4 \mathrm{~h}$.

\subsection{Characterization}

The particle size distribution of KP and AP was determined using a CILAS particle size analyzer, based on the laser scattering technique of suspensions in isopropyl alcohol and carbon tetrachloride in the ratio of 60/40.

The end of mix (EOM) viscosity and viscosity build-up of the propellant slurry was determined using a Brookfield viscometer, Model-HBT dial type, by inserting the T-C spindle (for the viscosity range 80-16000 $\mathrm{Pa} \cdot \mathrm{s}$ ) at a rotating speed of $2.5 \mathrm{rpm}$ at a predetermined temperature.

The density of cured samples was determined using a gas pycnometer, Thermo-Scientific, USA, using helium gas as the medium at $30^{\circ} \mathrm{C}$. The tap density of KP and AP was determined using a Tap Density Meter; model 
VTAP/MATIC-II of Veego Instruments, India.

The mechanical properties, such as tensile strength (TS), percentage elongation and elastic-modulus (E-modulus) of the cured propellant samples, were evaluated using dumb-bells on a tensile testing machine, Hounsfield, conforming to ASTM D638 type IV at a cross head speed of $50 \mathrm{~mm} / \mathrm{min}$ at ambient temperature.

Thermal property measurements of the cured samples were carried out on a differential scanning calorimeter (DSC), Model Q20, TA Instruments, USA, in the presence of UHP nitrogen having a flow rate of $50 \mathrm{~mL} / \mathrm{min}$.

The Solid Strand Burning Rate (SSBR) of cured propellant samples was determined using the acoustic emission technique at different pressures in an $\mathrm{N}_{2}$ atmosphere. Acoustic emission is defined as a transient wave generated by the rapid release of energy within a material [16]. An acoustic emission sensor converts the mechanical energy carried by the elastic wave into an electrical signal. The calorimetric value of the propellant samples was determined using a Bomb Calorimeter, Model 6200 of Parr, USA, following standard methods [17].

The impact and friction sensitivities of the cured propellant samples were determined using a Bundesanstalt fur Materialprufung (BAM) fall hammer (2 kg drop weight), Model No. BFH-10 (OZM, Czech Republic) and a BAM friction apparatus, Model No. FSKM-10 (OZM, Czech Republic), respectively. The samples $\left(40 \mathrm{~cm}^{3}\right)$ were prepared by chopping and sieving of the propellant through a 100 British Standard Sieve (BSS).

Electrostatic discharge (spark) sensitivity of the cured propellant samples was determined using an in-house developed instrument by applying $10000 \mathrm{~V}$ between the two electrodes.

\section{Incorporation of KP into the composite propellant formulation.}

All of the experimental mixing of the composite propellants was carried out at $5-\mathrm{kg}$ batch level in a vertical planetary mixer. A general method for the preparation of the propellant composition is described below.

A mixture of a prepolymer resin (504.5 g), i.e. HTPB, DOA plasticizer (195 g), antioxidant (2.5 g), i.e. 2-phenylnaphthylamine (Nonox-D), and bonding agent $(6.0 \mathrm{~g})$ (a mixture of 1,1,1-trimethylolpropane and 1,4-butanediol), except for the curing agent were mixed in the vertical planetary mixer (capacity $15 \mathrm{~L}$ ). The mixture was agitated for $0.5 \mathrm{~h}$, followed by mixing under vacuum for a further $0.5 \mathrm{~h}$ to drive out entrapped air. After this copper chromite $(17.5 \mathrm{~g})$ was added and mixed for $0.5 \mathrm{~h}$, followed by the addition of iron oxide (IO, $5 \mathrm{~g}$ ) and again mixing for $0.5 \mathrm{~h}$. Al powder $(850 \mathrm{~g})$ was then added and mixed thoroughly for $0.5 \mathrm{~h}$. After complete distribution of the Al powder in the binder matrix, 
a mixture (3385 $\mathrm{g}$ in total) of AP (in trimodal form; avg. particle sizes 300,50 and $6 \mu \mathrm{m}$ ) and $\mathrm{KP}$ were added and mixed. The overall mixing temperature was maintained at $40 \pm 2{ }^{\circ} \mathrm{C}$. After the addition of all of the solid ingredients, mixing of the composition was continued under vacuum for a further $0.5 \mathrm{~h}$. At this stage, TDI (34.5 g) was added and further mixed for $50 \mathrm{~min}$. The composition was then cast into $100 \mathrm{~mm}$ (Inner Diameter) moulds by vacuum casting and cured at $50{ }^{\circ} \mathrm{C}$ in a water jacketed oven for 7 days. The cured compositions were used for the determination of the mechanical and ballistic properties.

\section{Results and Discussion}

Initially, KP was fully characterized for purity and particle size and incorporated in the composite propellant formulation by partially replacing AP $(300 \mu \mathrm{m})$, from 2.5 to $10 \%$, in an $\mathrm{HTPB} / \mathrm{AP} / \mathrm{Al}$ based composition having $85.15 \%$ solids loading. The reason behind replacing $300 \mu \mathrm{m}$ AP with KP was that the latter's particle size has very little effect on burning rate of propellants as reported $[18,19]$. The composition details are given in Table 2.

Table 2. The formulation details of the propellant compositions

\begin{tabular}{|l|c|c|c|c|c|c|}
\hline \multicolumn{1}{|c|}{ Ingredients/ Composition } & $\begin{array}{c}\text { I } \\
{[\%]}\end{array}$ & $\begin{array}{c}\text { II } \\
{[\%]}\end{array}$ & $\begin{array}{c}\text { III } \\
{[\%]}\end{array}$ & $\begin{array}{c}\text { IV } \\
{[\%]}\end{array}$ & $\begin{array}{c}\text { V } \\
{[\%]}\end{array}$ & $\begin{array}{c}\text { VI } \\
{[\%]}\end{array}$ \\
\hline $\begin{array}{l}\text { HTPB+ DOA+ Bonding Agent }+ \\
\text { NONOX-D + TDI }\end{array}$ & 14.85 & 14.85 & 14.85 & 14.85 & 14.85 & 14.85 \\
\hline AP-300, $[\mu \mathrm{m}]$ & 24.1 & 21.6 & 19.1 & 16.6 & 14.1 & 24.1 \\
\hline AP-50, $[\mu \mathrm{m}]$ & 24.1 & 24.1 & 24.1 & 24.1 & 24.1 & 0 \\
\hline AP-6, $[\mu \mathrm{m}]$ & 19.5 & 19.5 & 19.5 & 19.5 & 19.5 & 19.5 \\
\hline Aluminium powder & 17 & 17 & 17 & 17 & 17 & 17 \\
\hline KP-50, $[\mu \mathrm{m}]$ & 0 & 2.5 & 5 & 7.5 & 10 & 24.1 \\
\hline Copper chromite & 0.35 & 0.35 & 0.35 & 0.35 & 0.35 & 0.35 \\
\hline Iron oxide & 0.10 & 0.10 & 0.10 & 0.10 & 0.10 & 0.10 \\
\hline
\end{tabular}

\subsection{Characterization of KP}

The purity of KP was determined by chemical analysis following the standard method [20] and was found to be $99.5 \%$ (impurities included $\mathrm{Na} / \mathrm{K}$ salts of chloride, chlorate, sulphate, etc.). The results revealed that the mean diameter of KP was around $50 \mu \mathrm{m}$ (CILAS particle size analyzer). The tap density of AP and KP were determined using a Tap Density Meter and the data are presented in Table 3. The data revealed that the KP had a higher tap density than the AP 
fine and AP coarse fractions. The tap density of a powder is a measure of its packing in a slurry when mixed with a binder.

Table 3. Data on the tap density of potassium perchlorate and ammonium perchlorate

\begin{tabular}{|c|c|}
\hline Ingredient- $\mu \mathrm{m}$ & Tap density, $\left[\mathrm{g} / \mathrm{cm}^{3}\right]$ \\
\hline AP-300 & 1.316 \\
\hline AP-50 & 1.000 \\
\hline AP-6 & 0.676 \\
\hline KP-50 & 1.500 \\
\hline
\end{tabular}

Table 4. Data on the viscosity, mechanical and ballistic properties of the compositions studied

\begin{tabular}{|c|c|c|c|c|c|c|c|c|c|}
\hline 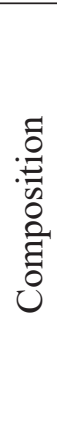 & 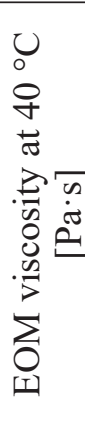 & 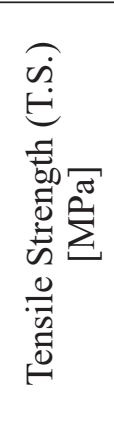 & 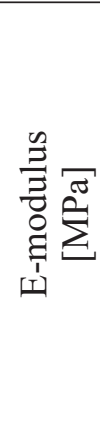 & 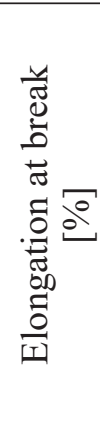 & 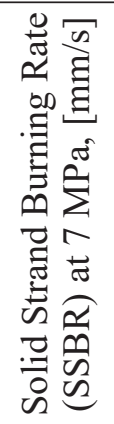 & 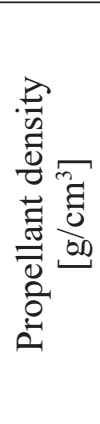 & 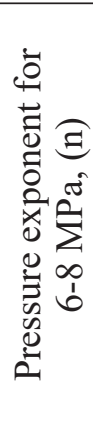 & 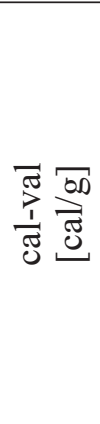 & 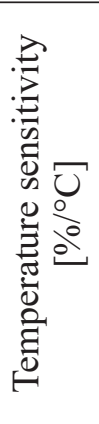 \\
\hline $\mathrm{I}$ & 1008 & 0.843 & .223 & 42.0 & 13.80 & 1.75 & 0.4 & 1563 & 0.1 \\
\hline II & 960 & 0.719 & 3.063 & 32.26 & 16.20 & 1.764 & 0.45 & 1538 & 0.13 \\
\hline III & 912 & 0.9024 & 3.958 & 26.22 & 17.40 & 1.777 & 0.4 & 1526 & 0.12 \\
\hline IV & 864 & 0.984 & 4.643 & 25.94 & 18.20 & 1.780 & 0.50 & 1510 & 0.11 \\
\hline $\mathrm{V}$ & 820 & 0.678 & 2.370 & 30.84 & 20.50 & 1.792 & 0.52 & 1495 & 0.09 \\
\hline VI & 672 & 0.564 & 2.157 & 26.80 & 20.60 & 1.841 & 0.55 & 1450 & 0.07 \\
\hline
\end{tabular}

\subsection{Effect of KP content on the viscosity build-up}

Different composite propellant formulations were prepared to study the behaviour of the EOM viscosity caused by varying the KP content from $2.5-10 \%$, are presented in Table 4. It is clear from Table 4 that a decreasing trend in EOM viscosity was observed as the KP content was increased from 2.5 to $10 \%$. This trend was found to be more promising in the case of $24.1 \% \mathrm{KP}$ (on replacement of $50 \mu \mathrm{m} \mathrm{AP}$ ), where the value of EOM was $672 \mathrm{~Pa} \cdot \mathrm{s}$ at $40{ }^{\circ} \mathrm{C}$, compared to $1008 \mathrm{~Pa} \cdot \mathrm{s}$ at $40{ }^{\circ} \mathrm{C}$ for the standard composition (Composition I). The decreasing trend in viscosity may be due to the higher tap density of $\mathrm{KP}\left(1.5 \mathrm{~g} / \mathrm{cm}^{3}\right)$ compared to AP fine $-50 \mu \mathrm{m}\left(1.0 \mathrm{~g} / \mathrm{cm}^{3}\right)$. The higher tap density of $\mathrm{KP}$ is thus reflected in 
a lowering of the viscosity of the propellant slurry containing KP, due to better packing. The lowering in the viscosity may help in increasing the solids loading of the propellant compositions, which can result in better performance in terms of density and specific impulse.

\subsection{Effect of KP content on the mechanical properties}

The mechanical properties of the cured propellants are presented in Table 4. The data revealed that the values of E-modulus and tensile strength of the cured propellant with $10 \% \mathrm{KP}$ were $2.370 \mathrm{MPa}$ and $0.678 \mathrm{MPa}$, respectively. The percentage elongation was found to be $30.84 \%$. It is clear from these data that they are on a par with the standard composition (Composition I) having a single oxidizer, i.e. AP.

The results of determination of density of the propellant are presented in Table 4, which clearly indicates that the density of the propellant increases as the KP content increases due to the higher density of KP compared to AP.

\subsection{Effect of KP on the thermal properties}

The DSC thermograms obtained for pure AP, KP and mixtures of AP and KP are shown in Figures 1, 2 and 3, respectively. The DSC thermogram of pure AP (Figure 1) revealed that there is a sharp endotherm at $243.21{ }^{\circ} \mathrm{C}$, which indicates the phase change of AP from monoclinic to orthorhombic. In addition, two exothermic peaks are found at $291.71{ }^{\circ} \mathrm{C}$ and $464.07{ }^{\circ} \mathrm{C}$, indicating the decomposition temperatures of AP. In the same way, the DSC thermogram of pure KP (Figure 2) showed a small endothermic peak at $303.13{ }^{\circ} \mathrm{C}$ followed by an exothermic peak at $620.77^{\circ} \mathrm{C}$, suggesting that the thermal stability of $\mathrm{KP}$ is better than that of AP. On the other hand, the mixture having $15 \% \mathrm{KP}$ and $85 \%$ AP (corresponding to $10 \% \mathrm{KP}$ in the propellant) showed an endothermic peak at $243.93{ }^{\circ} \mathrm{C}$ and two exothermic peaks at $291.78{ }^{\circ} \mathrm{C}$ and $434.22{ }^{\circ} \mathrm{C}$, clearly indicating the effect of KP on the thermal decomposition of AP (Figure 3 ). 


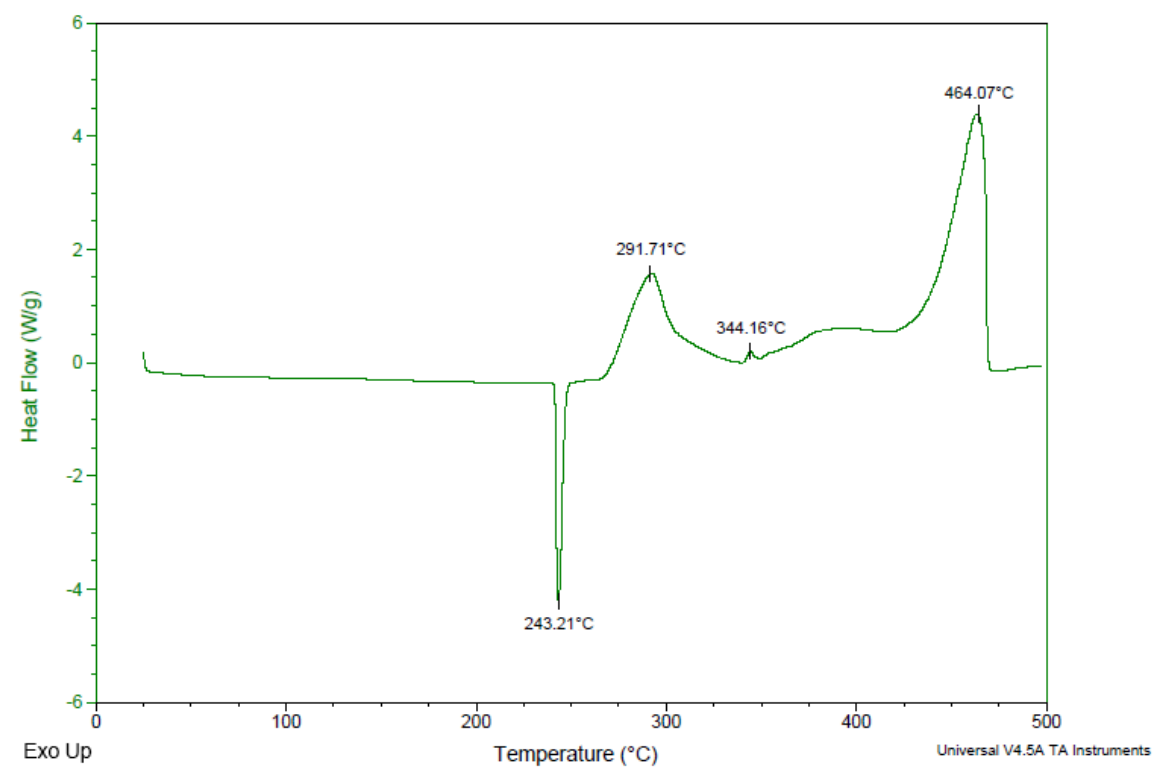

Figure 1. Differential scanning calorimeter thermogram of pure AP.

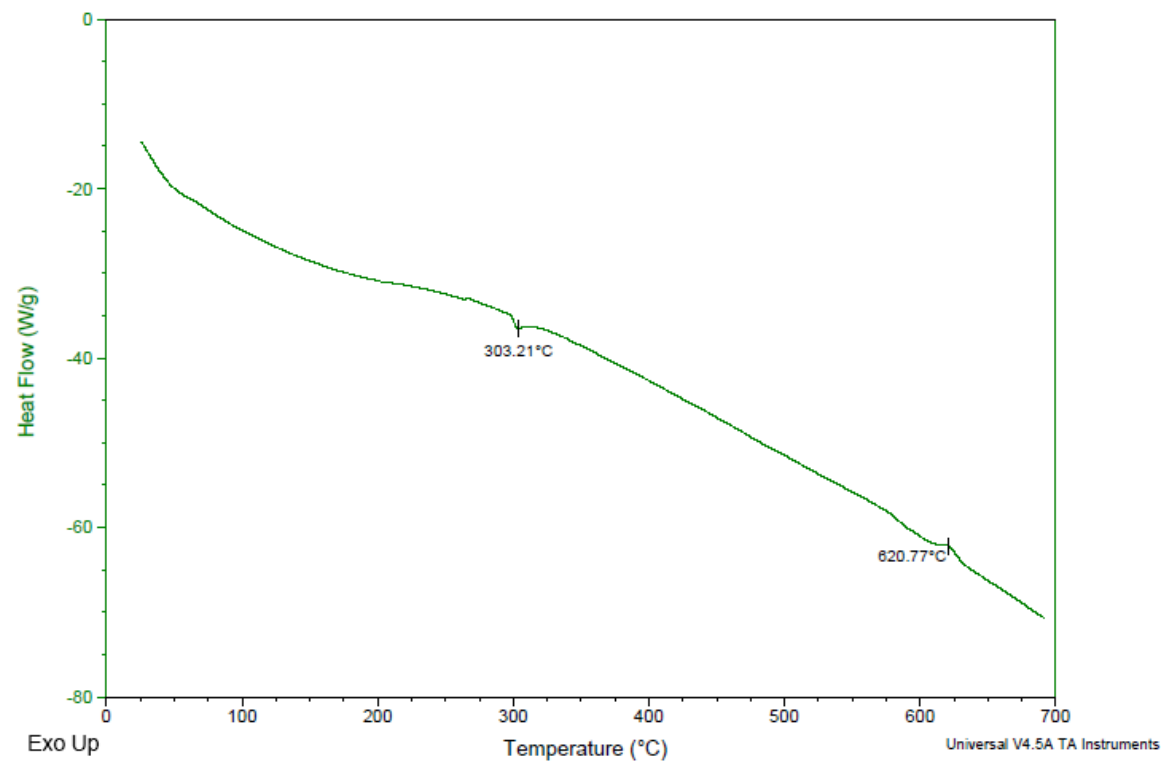

Figure 2. Differential scanning calorimeter thermogram of pure KP. 


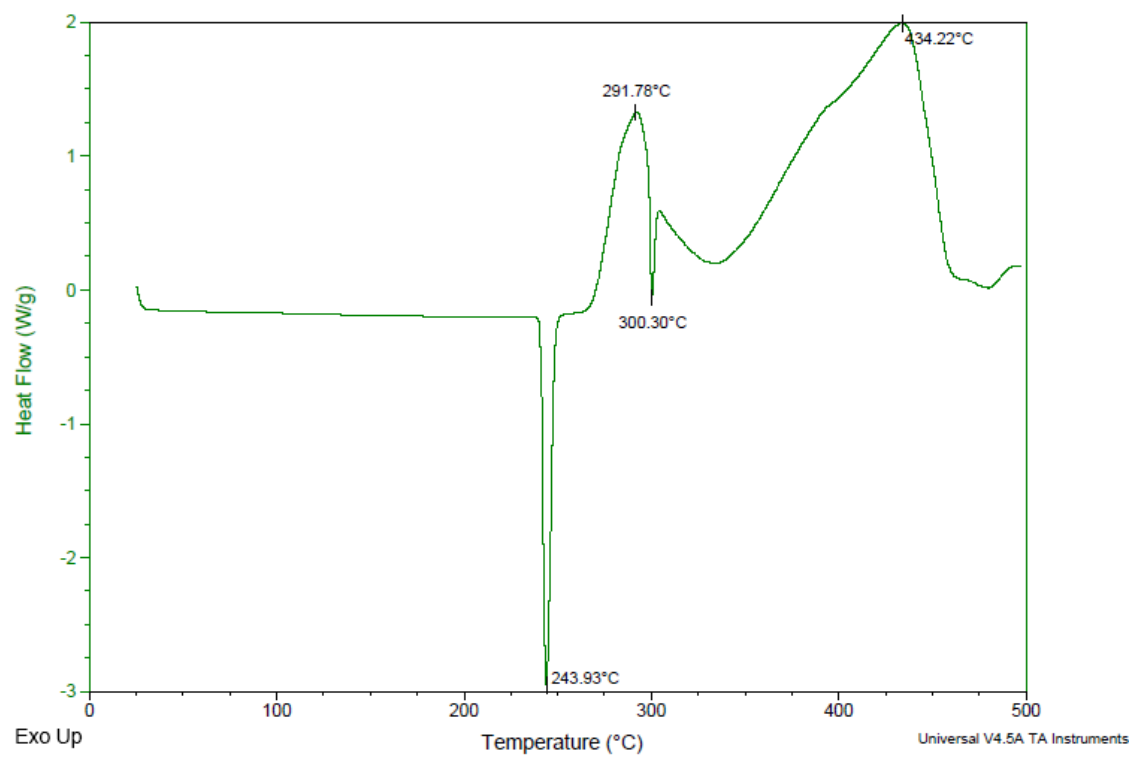

Figure 3. Differential scanning calorimeter thermogram of an AP/KP mixture $(85 / 15)$ corresponding to $10 \% \mathrm{KP}$ in the composition.

To study further the effect of KP on the thermal decomposition of AP, DSC thermograms with AP and KP mixtures corresponding to 5, 10, 15, 24.1 and $33.85 \% \mathrm{KP}$ in the compositions were generated, and the corresponding important endotherms/exotherms are given in Table 5. It is clear from the table that as the percentage of KP increases, the second exothermic peak of AP shifts towards lower temperatures, clearly indicating an effect of KP on the thermal decomposition of AP. Furthermore, compositions based on HTPB/AP/Al with $\mathrm{KP}(10 \%)$ partially replacing AP, were also studied by DSC and the thermograms obtained are shown in Figures 4 and 5, respectively. The DSC thermograms clearly revealed that the addition of KP causes a further reduction in the onset temperature of the exothermic peaks. Thus, the DSC study demonstrated that the addition of KP to the standard composite propellant formulation based on $\mathrm{HTPB} / \mathrm{AP} / \mathrm{Al}$, causes an appreciable reduction in the thermal temperatures, which ultimately help in the combustion of the propellant. 
Table 5. Thermogram data at different ratios of AP/KP using Differential Scanning Calorimetry (DSC)

\begin{tabular}{|l|c|c|c|c|c|}
\hline $\begin{array}{c}\text { AP/KP } \\
(\% \mathrm{KP} \text { in composition) }\end{array}$ & $\begin{array}{c}92.7 / 7.3 \\
(5 \%)\end{array}$ & $\begin{array}{c}85 / 15 \\
(10 \%)\end{array}$ & $\begin{array}{c}78 / 22 \\
(15 \%)\end{array}$ & $\begin{array}{c}65 / 35 \\
(24.1 \%)\end{array}$ & $\begin{array}{c}50 / 50 \\
(33.85 \%)\end{array}$ \\
\hline Endotherm-I, $\left[{ }^{\circ} \mathrm{C}\right]$ & 244.07 & 243.93 & 243.02 & 242.87 & 242.37 \\
\hline Endotherm-II, $\left[{ }^{\circ} \mathrm{C}\right]$ & 299.69 & 300.30 & 299.87 & 300.43 & 300.21 \\
\hline Exotherm-I, $\left[{ }^{\circ} \mathrm{C}\right]$ & 292.68 & 291.78 & 291.79 & 293.10 & 291.46 \\
\hline Exotherm-II, $\left[{ }^{\circ} \mathrm{C}\right]$ & 457.99 & 434.22 & 410.84 & 391.54 & 384.47 \\
\hline
\end{tabular}

The calorimetric values (cal-val) of the propellant samples were also determined using a Bomb Calorimeter and the data obtained are given in Table 4. The data revealed that as the KP content in the propellant was increased, the cal-val decreased accordingly. This may be attributed to the lower heat of formation of KP compared to AP.

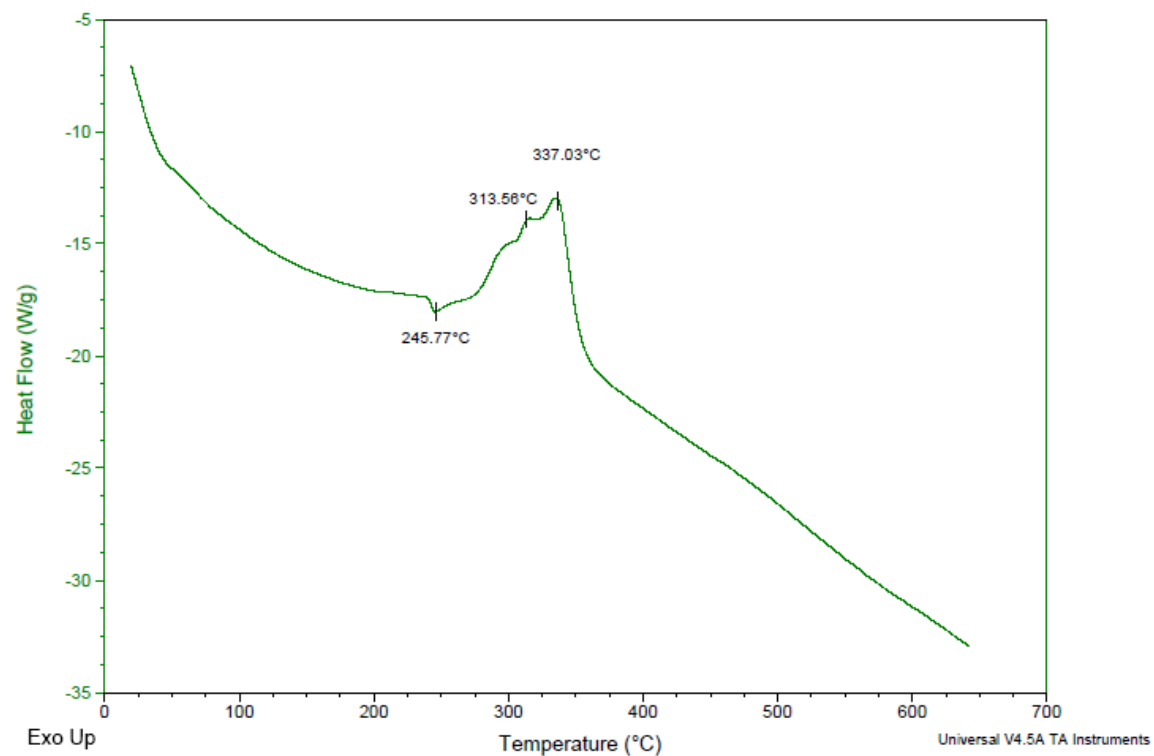

Figure 4. Differential scanning calorimeter thermogram of the standard propellant Composition I. 


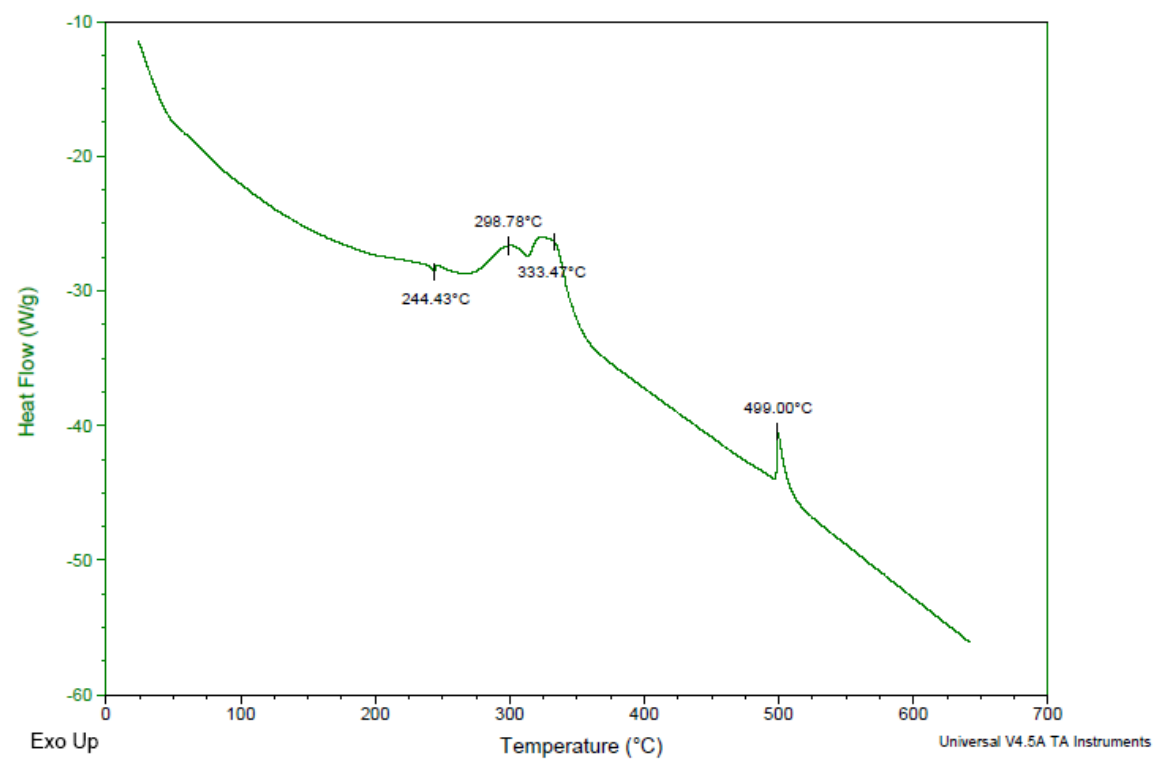

Figure 5. Differential scanning calorimeter thermogram of propellant Composition V with $10 \% \mathrm{KP}$.

\subsection{Effect of KP on the ballistic properties}

Ballistic properties of the developed compositions, such as the burning rate, were determined using an acoustic emission technique at $7 \mathrm{MPa}$ and the data obtained are given in Table 4. The data revealed that there is a gradual increase in the burning rate with increasing percentage of KP up to the $10 \%$ level, at which point it corresponds to more than $35 \%$ enhancement in the burning rate over the standard composition (Composition I). Enhancement in the burning rate beyond $10 \% \mathrm{KP}$ content was not appreciable for two reasons, namely, the higher oxygen balance and lower heat of formation values of KP compared to AP (Table 1). The heat of formation of KP is $-430.12 \mathrm{~kJ} / \mathrm{mol}$ compared to $-295.31 \mathrm{~kJ} / \mathrm{mol}$ for AP. The lower heat of formation of KP may contribute to it acting as a heat sink during the burning of the propellant. On the other hand, the oxygen balance of $\mathrm{KP}$ is $+46.2 \%$ whereas the oxygen balance of AP is $+34.04 \%$. However, the increase in oxygen balance of the oxidizer is balanced by the higher negative heat of formation; therefore, beyond the $10 \%$ level of KP in the composition, no appreciable burning rate increase was observed. Furthermore, it has also been reported that at lower concentrations of $\mathrm{KP}, \mathrm{K}^{+}$ions catalyse the condensed phase decomposition of AP which may result in an enhancement in the burning rate $[10,11]$. 
The pressure exponents (n-value) of the compositions were calculated in the pressure range 6-8 $\mathrm{MPa}$ and is reported in Table 4. It is clear from the table that as the percentage of KP in the compositions increases from 0 to $24.1 \%$, the pressure exponent also increases from 0.41 to 0.55 .

The temperature sensitivities of the compositions were determined by measuring the burning rate at 10,25 and $50{ }^{\circ} \mathrm{C}$ at $7 \mathrm{MPa}$ under a nitrogen atmosphere using the following equation [21] and the data obtained are presented in Table 4.

$$
\sigma_{p}=\frac{1}{\dot{r}} \frac{d \dot{r}}{d T}
$$

where: $\sigma_{p}$ is temperature sensitivity, $\dot{r}$ is the burning rate and $T$ is temperature.

It is clear from the table that, as the percentage of KP increases in the propellant compositions, the temperature sensitivity decreases accordingly. Furthermore, the decrease in temperature sensitivity may decrease the erosive behaviour of compositions based on KP.

The ballistic performance in terms of specific impulse $\left(\mathrm{I}_{\mathrm{sp}}\right)$ was evaluated for the composition having $10 \% \mathrm{KP}$ as well as for the standard composition (Composition I) at 70:1. The results revealed that the $10 \% \mathrm{KP}$ based composition gave an $\mathrm{I}_{\mathrm{sp}}$ of $239.8 \mathrm{~s}$, whereas the standard composition gave $240.0 \mathrm{~s}$ (with an accuracy of $\pm 0.5 \mathrm{~s}$ ).

\subsection{Effect of KP on the sensitivity properties}

The impact, friction and electrostatic discharge (spark) sensitivities were also measured for the standard composition (Composition I) and the composition having 10\% KP (Composition V), following standard procedures and the data obtained are presented in Table 6 . The data revealed that the KP based composition (Composition V) is less sensitive towards impact and friction than the standard composition (Composition I), however both compositions were found to be insensitive to electrostatic discharge, up to $5 \mathrm{~J}$.

Table 6. Data on the impact, friction and electrostatic discharge (spark) sensitivities of the propellant compositions

\begin{tabular}{|l|c|c|c|}
\hline Composition & $\begin{array}{c}\text { Impact sensitivity } \\
{[\mathrm{N} \cdot \mathrm{m}]}\end{array}$ & $\begin{array}{c}\text { Friction } \\
\text { Sensitivity } \\
{[\mathrm{N}]}\end{array}$ & $\begin{array}{c}\text { Electrostatic discharge } \\
\text { (spark) sensitivity } \\
{[\mathrm{J}]}\end{array}$ \\
\hline Composition I & 11.4 & 84 & 5 \\
\hline Composition V & 15 & 120 & 5 \\
\hline
\end{tabular}




\section{Conclusions}

A successful attempt has been made to use KP as a ballistic modifier in a composite propellant formulation based on $\mathrm{HTPB} / \mathrm{AP} / \mathrm{Al}$, by partially replacing AP without affecting propellant's performance. These formulations were studied in detail for their mechanical, thermal and ballistic properties. The data on the mechanical properties revealed that no change occurred in comparison to the standard composition (Composition I), however, the thermal stability decreased as the KP content was increased. The data on the burning rate revealed that there was a $35 \%$ enhancement over the standard composition (Composition I) with $10 \% \mathrm{KP}$, whereas the temperature sensitivity of the compositions was reduced on incorporating KP, from 0.18 (standard composition) to $0.07 \%$ ( $24 \% \mathrm{KP}$ ). The data on the performance in terms of the specific impulse revealed that the composition having $10 \% \mathrm{KP}(239.8 \mathrm{~s})$ gave same specific impulse as the standard composition ( $240 \mathrm{~s})$. Thus, the developed composition may find application where a high burning rate is required, without compromising the performance.

\section{Acknowledgements}

Authors would like to thank Mr. S. N. Jawalkar for providing full support during the propellant manufacture. They also thank Ms Garima Gupta, Mr. K. I. Dhabbe, and Ms L. S. Jawale for their support in the evaluation of the ballistic properties and rendering analytical help.

\section{References}

[1] Oberth A.E., Bruenner R.S., Polyurethane-based Propellants, in: Propellants, Manufacturing, Hazards and Testing, (Boyers C., Klager K., Eds.), American Chemical Society, Washington D.C., 1969, pp. 84-121; ISBN 9780841200890.

[2] Sayles D.C., Ala H., Solid Propellant Compositions and Method of Modifying Propellant Burning Rate Using Ferrocene Derivatives, US patent 3447981, 1969.

[3] Kishore K., Sunitha M.R. Effect of Transition Metal Oxide on Decomposition and Deflagration of Composite Solid Propellant System: A Survey, AIAA J., 1979, 17, 1118-1125.

[4] Bowker M., Practicalities: What is a Catalyst, in: The Basics and Application of Heterogeneous Catalysis, Oxford University Press, New York, 1998, pp. 32-62; ISBN 9780198559580.

[5] Boggs T.L., Zurn D.E., Cordes H.F., Covino J., Combustion of Ammonium Perchlorate and Various Inorganic Additive, J. Propul. Power, 1988, 4, $27-40$.

[6] Singh G., Pandey D.K., Studies on Energetic Compounds. Part 36: Evaluation of 
Transition Metal Salts of NTO as Burning Rate Modifiers for HTPB-AN Composite Solid Propellants, Combust. Flame, 2003, 135(1-2), 145-150.

[7] Gore G.M., Bhatewara R.G., Tipare K.R., Nazare A.N., Asthana S.N., Studies on Ferrocene Polyglycol Oligomer - Burning Rate Modifier for Composite Propellants, J. Propul. Power, 2004, 20(4), 758-760.

[8] Saravanakumar D., Sengottuvelan N., Narayanan V., Kandaswamy M., Varghese T.L., Burning Rate Enhancement of a High Energy Rocket Composite Solid Propellant Based on Ferrocene Grafted Hydroxyl-terminated Polybutadiene Binder, J. Appl. Polym. Sci., 2011, 119(5), 2517-2524.

[9] Bogs T.L., Kraeutle K.J., Zurn D.E., Decomposition, Pyrolysis, and Deflagration of Pure and Isomorphously Doped Ammonium Perchlorate, AIAA J., 1972, 10(1), $15-16$.

[10] Ishitha K., Ramakrishna P.A., Enhancing Composite Solid Propellant Burning Rates with Potassium Doped Ammonium Perchlorate - Part I, J. Propul. Power, 2014, 30(2), 277-284.

[11] Ishitha K., Ramakrishna P. A., Enhancing Composite Solid Propellant Burning Rates with Potassium Doped Ammonium Perchlorate - Part 2, J. Propul. Power, 2014, 30(4), 876-882.

[12] Seetharamacharyulu D., Verneker V.R.P., Mallya R.M., Combustion and Thermal Decomposition of a Binary Oxidiser System: Ammonium Perchlorate - Potassium Perchlorate, Combust. Sci. Technol., 1981, 27, 19-30.

[13] Dey A., Sikder A.K., Talawar M.B., Chottopadhyay S., Towards New Directions in Oxidizers/Energetic Fillers for Composite Propellants: an Overview, Cent. Eur. J. Energ. Mater., 2015, 12(2), 377-399.

[14] Dickinson L.A., Capener E.L.R., Kier J., Research on Unstable Combustion in Solid Propellant Rockets, Air Force Office of Scientific Research Washington, D.C. 20333, AD612178, 1965.

[15] Adicoff A., Ayres W.M., Hills M.E., McBride W.R., Modified Ammonium Perchlorate Incorporating Potassium, Permanganate, and Dichromate Dopants (u), Research Department, Naval Weapon Center, AD 518421, 1971.

[16] Gupta G., Jawale L., Mehilal, Bhattacharya B., Various Methods for the Determination of the Burning Rates of Solid Propellants - An Overview, Cent. Eur. J. Energ. Mater., 2015, 12(3), 593-620.

[17] Jawale L.S., Dey C., Mehilal, Gupta M., Bhattacharya B., Effect of Experiment Environment on Calorimetric Value of Composite Solid Propellants, Def. Sci. J., 2013, 63(5), 467-472.

[18] Beckstead M.W., Derr R.L., Price C.F., The Combustion of Solid Monopropellants and Composite Propellants, $13^{\text {th }}$ Symp. (Int.) on Combustion, The Combustion Institute, Pittsburgh, Russia, 1971, 1047-56.

[19] Klager K., Zimmerman G.A., Steady Burning Rate and Affecting Factors: Experimental Results, in: Nonsteady Burning and Combustion Stability of Solid Propellants, (Luca L.D., Price E., Summerfield M., Eds.), Progress in Astronautics and Aeronautics, Washington, D.C., 1992, Vol. 143, pp. 59-105; ISBN 1-56347-014-4. 
[20] Determination of Potassium Perchlorate Content, J.S.S. 6810-58:2000, Revision No. 2.

[21] Sutton P.G., Biblarz O., Solid Propellant Rocket Fundamentals, in: Rocket Propulsion Elements, John Wiley \& Sons, New York, 2000, pp. 417-473; ISBN 0471326429. 
